University of Nebraska - Lincoln

DigitalCommons@University of Nebraska - Lincoln

$12-1994$

\title{
Second Intermediate Host-Specificity of Haematoloechus complexus and Haematoloechus medioplexus (Digenea: Haematoloechidae)
}

Scott D. Snyder

University of Nebraska at Omaha, sdsnyder@mail.unomaha.edu

John J. Janovy Jr.

University of Nebraska - Lincoln, jjanovy1@unl.edu

Follow this and additional works at: https://digitalcommons.unl.edu/bioscijanovy

Part of the Parasitology Commons

Snyder, Scott D. and Janovy, John J. Jr., "Second Intermediate Host-Specificity of Haematoloechus complexus and Haematoloechus medioplexus (Digenea: Haematoloechidae)" (1994). John Janovy Publications. 23.

https://digitalcommons.unl.edu/bioscijanovy/23

This Article is brought to you for free and open access by the Papers in the Biological Sciences at DigitalCommons@University of Nebraska - Lincoln. It has been accepted for inclusion in John Janovy Publications by an authorized administrator of DigitalCommons@University of Nebraska - Lincoln. 


\title{
Second Intermediate Host-Specificity of Haematoloechus complexus and Haematoloechus medioplexus (Digenea: Haematoloechidae)
}

\author{
Scott D. Snyder and J. Janovy, Jr., School of Biological Sciences, University of Nebraska-Lincoln, Lincoln, Nebraska \\ $68588-0118$
}

\begin{abstract}
Second intermediate host-specificity was examined for 2 species of the frog lung fluke genus Haematoloechus. Nine species of freshwater arthropods were exposed to cercariae of $H$. complexus and $H$. medioplexus. Metacercariae of $H$. complexus developed in all arthropod species used. Metacercariae of $H$. medioplexus developed only in anisopteran odonate naiads. This difference in host utilization may have epizootiological implications. The potential development of $H$. complexus in a greater number of arthropods than $H$. medioplexus may increase the chances of ingestion of $H$. complexus by an anuran host. The range of arthropods parasitized by $H$. complexus indicates that host-specificity of the metacercarial stage of this fluke is not restricted by the phylogeny of aquatic arthropods.
\end{abstract}

Frog lung flukes of the genus Haematoloechus are generally considered to utilize only odonates as second intermediate hosts. For example, $H$. varioplexus encysts within members of the dragonfly genus Sympetrum in North America (Krull, $1931)$ and $H$. johnsoni is present in African anisopterans (Bourgat and Kulo, 1979). A few species of Haematoloechus have also been found to parasitize zygopterans. Haematoloechus longiplexus was reported from Lestes vigilax in Michigan by Krull (1932) and Grabda (1960) reported the European $H$. similis only from damselflies of the genus Coenagrion. Anisopteran and zygopteran odonates are distinguished on the basis of differing respiratory structures. Anisopteran (dragonfly) odonate naiads acquire oxygen by sucking water into the rectum, which has been modified as an organ of gas exchange. Zygopteran (damselfly) naiads utilize 3 external gills on the terminus of the abdomen for gas exchange.

Lung fluke metacercariae have rarely been found in non-odonate arthropods. Haematoloechus variegatus was reported by van Theil (1930) from larvae of the mosquito Anopheles maculipennis. Another species of Haematoloechus was found by Dollfus et al. (1960) to parasitize 2 species of the dipteran genus Culex as well as $A$. maculipennis. In addition, Combes (1968) experimentally infected 2 species of plecopteran larvae with $H$. pyrenaicus.

The present work examines experimentally the second intermediate host-specificity of 2 North American haematoloechids, $H$. complexus and $H$. medioplexus. Both parasites were obtained from the northern leopard frog Rana pipiens collected from Nevens Pond, a stock tank runoff pond in Keith County, Nebraska (SW 1/4, Sec. 2, T14N, R36W). Within this pond, H. complexus uses Physella virgata as its first intermediate host, 
and $H$. medioplexus parasitizes the planorbid snail Gyraulus parvus.

Laboratory infections of $H$. complexus were successfully established in Physella gyrina, $P$. heterostropha, and $P$. virgata, and Haematoloechus medioplexus infections were established in Promentus exacuous and G. parvus. Adult flukes used in these infections were identified according to Kennedy (1981), and eggs of these parasites were differentiated on the basis of size. Eggs of H. complexus from the Nevens Pond population are approximately $33 \mu \mathrm{m}$ long and eggs of $H$. medioplexus approximately $26 \mu \mathrm{m}$ in length. Parasite eggs were harvested by placing single adult worms in jars containing aged tap water. The jars were covered and the eggs allowed to sit for at least 7 days. Laboratory-reared snails were then placed in the jars along with a small amount of Tetra Min ${ }^{\circledR}$ slurry to encourage the snails to consume the eggs. Eggs of $H$. complexus were found hatched in the feces of G. parvus and the previously mentioned physids. Cercariae of this parasite were released only from the physids. Similarly, eggs of $H$. medioplexus were found hatched in the feces of the physids as well as $G$. parvus, but this parasite produced cercariae only in G. parvus and Pr. exacuous.

The cercariae of the 2 species differed according to size as well as host origin. Haematoloechus medioplexus cercariae were much smaller than those of $H$. complexus. The former cercariae had a body length approximately $98 \mu \mathrm{m}$, whereas $H$. complexus were approximately $169 \mu \mathrm{m}$ long (excluding the tail). The difference in size and host origin of cercariae from laboratory-infected snails allowed for identification of these parasite species when cercariae were collected from naturally infected snails from the Nevens Pond site.

Naturally and experimentally infected snails were individually isolated in $150-\mathrm{ml}$ plastic jars and fed a Tetra Min ${ }^{\circledR}$ slurry ad libitum. Water containing cercariae of 1 species was removed from all jars with shedding snails, pooled, and divided into aliquots, the volume of which varied according to the number of snails actively shedding cercariae on the day of the experiment and the number of arthropods available for exposure. The use of this protocol resulted in the exposure of different arthropod species to different numbers of cercariae. At least 20 cercariae were present in each jar, although the precise number was not counted. An effort was made to ensure that approximately the same number of the 2 different species of cercariae was used. The arthropods listed in Table I were placed in 200$\mathrm{ml}$ plastic jars along with the water containing the cercariae of 1 of the parasite species.

Arthropods used in these experiments came from a variety of natural populations. To ensure that these animals were not naturally infected, 10 individuals of each species were selected at the time of experimental exposure and dissected to check for the presence of metacercariae $\left(T_{\text {zero }}\right.$ control). In the case of Libellula sp., however, only 4 animals were dissected due to the small number of naiads collected. As an additional control, another group of 10 (4 in the case of Libellula sp.) was randomly selected from each group of arthropods and held in the laboratory in aged tap water $\left(T_{1}\right.$ control).

Between 5 and 8 days postexposure (depending on the heartiness of the different arthropods in the lab) both experimental and $T_{1}$ control arthropods were dissected and examined for the presence of metacercariae. Not all arthropods survived to the date of dissection.

Metacercariae of $H$. complexus were found in individuals of all 9 arthropod species exposed to cercariae (Table I). These arthropods represent 2 subphyla and 3 insect orders. Following laboratory exposure, metacercariae of $\mathrm{H}$. medioplexus were found only in the anisopteran odonates Anax junius and Libellula sp. In no instance were metacercariae of any species found in animals that served as controls. Table I lists the number of arthropods that harbored metacercariae and the number initially exposed to cercariae that survived to the dissection date.

Previous reports of second intermediate host utilization of $H$. complexus are limited to anisopteran and zygopteran odonates (Ingles, 1933; Krull, 1933; Dronen, 1975). The present study indicates that the metacercariae of $H$. complexus are generalists, able to utilize a much wider range of second intermediate hosts than previously believed. Haematoloechus medioplexus, however, was found to be a second intermediate host specialist, parasitizing only anisopteran odonates, a result consistent with earlier work (Krull, 1930, 1931).

A wide range of second intermediate host utilization by a generalist species might well increase the total number of infected arthropods in nature when compared to the number infected by a specialist. Thus, an anuran would have a better chance of ingesting a food item infected by the generalist than by the specialist. Members of the $R$. pipiens complex have been reported to 
eat ephemeropteran larvae, amphipods including Gammarus lacustris, chironomid midges, and a variety of adult and larval odonates (Drake, 1914; Knowlton, 1944; Kilby, 1945). It should be noted that some of the arthropods used in this study may never enter the diet of $R$. pipiens. For example, the mayflies Leptophlebia spp. generally occupy lotic habitats (Merritt and Cummins, 1978) where contact with $R$. pipiens is probably rare. What should be emphasized is the taxonomic range of arthropods susceptible to parasitism by $H$. complexus. This range indicates that $H$. complexus is likely able to parasitize almost any aquatic arthropod, including species of ephemeropterans that do co-occur with $R$. pipiens.

Field data lend tentative support to the idea that the generalist nature of $H$. complexus metacercariae may enable this parasite to infect more definitive hosts than the specialist $H$. medioplexus. Haematoloechus complexus had a higher prevalence than $H$. medioplexus in $18 R$. pipiens collected from Nevens Pond between March and September 1993. These frogs ranged in size from $45 \mathrm{~mm}$ to $100 \mathrm{~mm}$ snout-vent length. Haematoloechus complexus was present in 13 out of 18 (72.2\%) frogs, whereas $H$. medioplexus was present in only 6 of $18(33.0 \%)$. This difference is statistically significant when the data are analyzed using chi-square in a $2 \times 2$ contingency table (chi-square $=5.46, \mathrm{df}=1, P<0.05$ ). Furthermore, the relative density of $H$. complexus (6.4 flukes/frog) is greater than that of $H$. medioplexus (1.33 flukes/frog). Relative density data were distributed non-normally and were thus ranked and analyzed using Student's $t$-test. This procedure indicated a significant difference between the relative density of $H$. complexus and $H$. medioplexus $(t=5.24$, $\mathrm{df}=34, P<0.05)$. The difference between the mean intensity of $H$. complexus (8.9 flukes/infected frog) and $H$. medioplexus (4.0 flukes/infected frog) was not statistically significant when the data were ranked and analyzed using Student's $t$-test $(t=1.88$, df $=17, P<0.1$ ).

The differences in prevalence and relative density could obviously be due to factors unrelated to second intermediate host utilization, for example differences in the size of first intermediate host populations or differences in anuran susceptibility to the parasites. However, these results do suggest the potential epizootiological importance of the relatively broad second intermediate host range of $H$. complexus.
TABLE I. Results of experimental exposures of arthropods to cercariae of Haematoloechus complexus and H. medioplexus.

\begin{tabular}{|c|c|c|}
\hline \multirow[b]{2}{*}{ Experimental arthropods } & \multicolumn{2}{|c|}{$\begin{array}{l}\text { Number infected/number } \\
\text { of exposed survivors }\end{array}$} \\
\hline & $\begin{array}{l}\text { Haematoloechus } \\
\text { complexus }\end{array}$ & $\begin{array}{l}\text { Haematoloechus } \\
\text { medioplexus }\end{array}$ \\
\hline \multicolumn{3}{|l|}{ Insecta } \\
\hline \multicolumn{3}{|l|}{ Odonata: Anisoptera } \\
\hline Anax junius & $8 / 8$ & $7 / 9$ \\
\hline Libellula sp. & $3 / 3$ & $3 / 3$ \\
\hline \multicolumn{3}{|l|}{ Odonata: Zygoptera } \\
\hline Enallagma civile & $3 / 3$ & $0 / 6$ \\
\hline Ischnura verticalis & $10 / 10$ & $0 / 10$ \\
\hline \multicolumn{3}{|l|}{ Ephemeroptera } \\
\hline Leptophlebia sp. & $6 / 6$ & $0 / 9$ \\
\hline \multicolumn{3}{|l|}{ Diptera: Chironomidae } \\
\hline Eukiefferiella sp. & $6 / 8$ & $0 / 9$ \\
\hline \multicolumn{3}{|l|}{ Crustacea } \\
\hline \multicolumn{3}{|l|}{ Isopoda } \\
\hline Asellus intermedius & $8 / 10$ & $0 / 10$ \\
\hline Asellus militaris & $6 / 10$ & $0 / 10$ \\
\hline \multicolumn{3}{|l|}{ Amphipoda } \\
\hline Gammarus lacustris & $5 / 6$ & $0 / 9$ \\
\hline
\end{tabular}

Combes (1968) found metacercariae of $H$. pyrenaicus encysted only within the respiratory organs of both plecopteran larvae and anisopteran naiads. He speculated that the ability of $H$. pyrenaicus to parasitize both types of insects was related to the similar nature of gill structure among these 2 animals. Thus, similarity of encystment sites was thought to be more important than host phylogeny in determining host suitability. In the present study, $H$. medioplexus metacercariae were found only in the branchial baskets of anisopteran hosts. Haematoloechus medioplexus was unable to infect other gill-bearing arthropods. Metacercariae of $H$. complexus, however, were found throughout the bodies of infected arthropods, encysting in the heads, thoraces, and abdomens, as well as within the appendages of many second intermediate hosts. Haematoloechus complexus metacercariae did encyst within the gills of anisopteran odonate naiads and freshwater isopods but were also present throughout the rest of the bodies of these animals. The broad taxonomic range of second intermediate hosts utilized by $H$. complexus indicates that host phylogeny is not a dominant factor in determining suitability among aquatic arthropods for this parasite species.

The authors thank Liz Snyder and Lyndon Ruhnke for assistance in the collection of spec- 
imens. Thanks also go to R. E. Clopton and Aris Efting for help in specimen identification. The use of facilities at Cedar Point Biological Station is gratefully acknowledged. This study was supported in part by the Ashton C. Cuckler Fellowship.

\section{LITERATURE CITED}

Bourgat, R., AND S. D. Kulo. 1979. Cycle biologique d'Haematoloechus johnsoni Bourgat, 1977, (Trématode) parasite pulmonaire de Dicroglossus occipitalis (Günther, 1858) (Amphibien, Anoure) au Togo. Revue Suisse de Zoologie 86: 467-472.

COMBEs, C. 1968. Biologie, écologie des cycles et biogéographie de digènes et monogènes d'amphibiens dans l'est des Pyrénées. Mémoires du muséum national d'histoire naturelle 51: 1-195.

Dollfus, R. P., J. M. DoBy, AND P. LAURENT. 1960. Sur une xiphidiocercaire parasitant Limnaea trunculata (O. F. Müller) en haute-savoie et s'enkystant dans des larves de moustiques. Bulletin de la Societe Zoologique de France 85: 331-347.

Drake, C. J. 1914. The food of Rana pipiens Shreber. The Ohio Naturalist 14: 257-269.

Dronen, N. O. 1975. The life cycle of Haematoloechus coloradensis Cort 1915 (Digenea: Plagiorchiidae), with emphasis on host susceptibility to infection. Journal of Parasitology 61: 657-660.

GRABDA, B. 1960. Life cycle of Haematoloechus similis (Looss, 1899) (Trematoda: Plagiorchiidae). Acta Parasitologica Polonica 8: 357-367.

INGLES, L. G. 193?. Studies on the structure and lifehistory of Ostiolum oxyorchis (Ingles) from the California red-legged frog, Rana aurora Draytoni.
University of California Publications in Zoology 39: 135-161.

KENNEDY, M. J. 1981. A revision of the genus Haematoloechus Loos, 1899 (Trematoda: Haematoloechidae) from Canada and the United States. Canadian Journal of Zoology 59: 1836-1846.

KILBY, J. K. 1945. A biological analysis of the food and feeding habits of two frogs, Hyla cinerea cinerea and Rana pipiens sphenocephala. Quarterly Journal of the Florida Academy of Sciences 8: 71104.

Knowlton, G. F. 1944. Some insect food of Rana pipiens. Copeia 1944: 119.

KRULL, W. H. 1930. The life history of two North American frog lung flukes. Journal of Parasitology 16: $207-212$.

- 1931. Life history studies on two frog lung flukes, Pneumonoeces medioplexus and Pneumobites parviplexus. Transactions of the American Microscopical Society 50: 215-277.

1932. Studies on the life history of Haematoloechus longiplexus (Stafford). Zoologischer Anzeiger 99: 231-239.

1933. Studies on the life history of a frog lung fluke, Haematoloechus complexus (Seely, 1906) Krull, n. comb. Zeitschrift für Parasitenkunde 6: 193-206.

MERrit, R. W., AND K. W. CUMmins. 1978. An introduction to the aquatic insects of North America. Kendall/Hunt Publishing Company, Dubuque, Iowa, $441 \mathrm{p}$.

vaN THEIL, P. H. 1930. Die entwicklung von Agamodistomum anophelis zum Pneumonoecues variegatus Rud. Zentralblatt für Backteriologie, Parasitenkunde, und Infektionskrankheiten 117: 103112. 